Food, Dairy and Home Economic Research

http:/www.journals.zu.edu.eg/journalDisplay.aspx?Journalld=1\&queryType=Master

\title{
EFFECT OF GAMMA RADIATION ON PHYTOCHEMICAL COMPOUNDS IN FABA BEAN (Vicia faba L.)
}

\author{
Amr Kh. Ali ${ }^{*}$, A.O. Toliba ${ }^{2}$, A.H. Rady ${ }^{1}$ and K.M. El-Sahy ${ }^{2}$ \\ 1. Nuclear Res. Cent., Atomic Energy Authority, Egypt \\ 2. Food Sci. Dept., Fac. Agric., Zagazig Univ., Egypt
}

Received: 22/04/2019; Accepted: 13/05/2019

\begin{abstract}
The objective of the present study was to investigate the effect of gamma radiation on phytochemical compounds in faba bean. Samples of faba bean seeds were exposed to gamma radiation at doses of $0,1,2,3,4,5,6,7,8,9$ and $10 \mathrm{kGy}$. Then the contents of total phenolic and flavonoid compounds in non-irradiated and irradiated samples were determined. The contents of total phenolic compounds in samples of non-irradiated faba bean was found to be $220.55 \pm 0.040 \mu \mathrm{g}$ gallic acid equivalent/g dry matter, while the total flavonoids in non-irradiated samples were found to be $106.33 \pm 0.450 \mu \mathrm{g}$ quercetin equivalent/g dry matter. Exposing faba bean seeds to ascending doses of gamma irradiation induced significant gradual increases in the contents of total phenolic and flavonoid contents. The maximum increases were observed in samples irradiated at dose of $9 \mathrm{kGy}$ showing increase by about $183 \%$ and $283 \%$ in phenolic and flavonoid contents, respectively. Based on these results, phenolic and flavonoid compounds in the ethanolic extracts of non- irradiated faba bean seeds and those irradiated at dose of $9 \mathrm{kGy}$ were fractionated and quantified by High Performance Liquid Chromatography (HPLC). The results showed that 21 phenolic and 14 flavonoid compounds could be separated and quantified from the extract of non-irradiated faba bean seeds by HPLC. The same compounds were identified in the extract of seeds irradiated at $9 \mathrm{kGy}$ dose but at increased concentrations. The effect of gamma irradiation on the contents of macronutrients in seeds as well as their water absorption properties was also determined. Significant differences were observed in the proximate chemical composition between samples of non-irradiated faba beans and those irradiated at doses up to $10 \mathrm{kGy}$. However, irradiation treatments generally induced slight, but statistically significant, increases in the values of water absorption properties as measured gravimetrically (hydration properties) and volumetrically (swelling properties). From the obtained results for total phenolic and flavonoid contents in non-irradiated and irradiated faba bean, it is clear that irradiation dose of $9 \mathrm{kGy}$ can be selected as an optimal dose for increasing of these phytochemicals in faba bean.
\end{abstract}

Key words: Faba beans, phenolic compounds, flavonoids, chemical composition, water absorption.

\section{INTRODUCTION}

Faba bean is a worldwide important crop constituting an important part of diet in several countries. In Egypt, faba bean constitutes a common staple food eaten in different popular dishes by both rich and poor consumers (EIMergawi and Taie, 2014; Chaieb et al., 2015; Abu-Reidah et al., 2017).

\footnotetext{
*Corresponding author: Tel. : +201003796174

E-mail address: Eng_Amr555@yahoo.com
}

There is a constant changing in consumer's eating habits with a new trend of consumption for the natural and healthy diet including vegetables which help to prevent diseases (De Rosas et al., 2019). Due to its positive nutritional benefits, a growing interest is devoted to faba bean (Turco et al., 2016). Faba bean is excellent source of many nutrients (Grela et al., 2017; Kan et al., 2018; Mattila et al., 2018). 
Furthermore, faba bean is rich in many functional phenolic and flavonoid compounds (Magalhães et al., 2017; Kan et al., 2018; Kwon et al., 2018). These compounds play an important role in human health and nutrition having the advantage of reducing the risk of several diseases including cancers and cardiovascular diseases (Hu et al., 2015; Guti Errez-Grijalva et al., 2016; Ha, 2016; Martins and Ferreira, 2017).

Food irradiation is an efficient technology that can address both food safety and quality. There is increasing interest in this technology which approved in more than 50 countries including Egypt and more than 60 products are being irradiated in the world (Osterholm and Norgan, 2004; Kume and Todoriki, 2013; Woodside, 2015; Ehlermann, 2016; Maherani et al., 2016). Studies have shown that irradiation treatment can increase the contents of certain phytochemicals and enhance the biological value of some plants (Zevallos-Concha et al., 2016; Vardhan and Shukla, 2017; Pereira et al., 2018 a,b). Therefore, the objective of the present study was to investigate the effect of gamma radiation on phenolic and flavonoid compounds in faba bean seeds and assessing the effect of irradiation treatments on macronutrients in seeds as well as their hydration properties.

\section{MATERIALS AND METHODS}

\section{Materials}

Whole faba bean seeds (Vicia faba L.) were obtained from a local market at Bilbies City Sharkia Governorate, Egypt. The seeds were carefully cleaned by hand to remove any foreign materials, divided into appropriate samples of about $200 \mathrm{~g}$ and packaged in polyethylene pouches. Pouches were sealed by heat and transferred for irradiation treatment. Solvents and chemicals were of analytical grade and purchased from El-Gomhoria Company for Chemicals and Drugs, Cairo, Egypt.

\section{Irradiation Treatment}

Packaged samples of faba bean seeds were exposed to gamma radiation at doses of $0,1,2$, $3,4,5,6,7,8,9$ and $10 \mathrm{kGy}$. Irradiation treatment was carried out using a ${ }^{60} \mathrm{Co}$ Russian gamma chamber (providing a dose rate of 670.687 Gray $/ \mathrm{hr}$.) belonging to Cyclotron
Project, Nuclear Research Center, Atomic Energy Authority, Egypt.

\section{Analytical Methods}

\section{Phenolic and flavonoid compounds}

\section{Ethanolic extraction of phenolic compounds}

Samples of non-irradiated and irradiated faba bean seeds under investigation were milled into a fine powder to pass a $0.4 \mathrm{~mm}$ mesh size screen. The ground samples were defatted in a Soxhlet apparatus for 6-8 hr., using n-hexane, then defatted samples were dried in an oven at $45^{\circ} \mathrm{C}$ for $1 \mathrm{hr}$. The extraction of phenolics was carried out as described by Oomah et al. (2008) with some modifications. In this method, 200 mg portion of the defatted ground sample were extracted with $8 \mathrm{ml}$ of aqueous ethanol $80 \%$ $(V / V)$ by constant magnetic stirring for $2 \mathrm{hr}$., at room temperature followed by centrifugation at $1100 \mathrm{~g}$ for $10 \mathrm{~min}$. To obtain all phenolic compounds, extraction was performed three times, then the obtained three supernatants were combined and evaporated under vacuum using rotary evaporator to a volume of about $25 \mathrm{ml}$. The obtained ethanolic extracts were stored at $18^{\circ} \mathrm{C}$ in the dark until analysis.

\section{Determination of total phenolic compounds}

The Folin-Ciocalteu method was applied for the determination of total phenolic compounds according to Arabshahi-Delouee and Urooj (2007). Briefly, $200 \mu \mathrm{l}$ of the ethanolic extract were mixed with $1 \mathrm{ml}$ of Folin-Ciocalteu's reagent ( $1 \mathrm{ml}$ reagent with $9 \mathrm{ml}$ distilled water) for $5 \mathrm{~min}$, then $1.5 \mathrm{ml}$ distilled water and $1 \mathrm{ml}$ of $75 \mathrm{~g}^{-1} \quad \mathrm{Na}_{2} \mathrm{CO}_{3}$ solution were added. After shaking at ambient temperature for $60 \mathrm{~min}$, the absorbance at $760 \mathrm{~nm}$ was measured by the spectrophtometer. Gallic acid was used as a standard for the calibration curve and the total phenolic content was expressed as $\mu \mathrm{g}$ gallic acid equivalent (GAE) /g dry matter.

\section{Determination of total flavonoid content (TFC)}

The contents of total flavonoids were determined as described by Ordon et al. (2006). A $0.5 \mathrm{ml}$ aliquot of $\mathrm{AlCl}_{3}$ ethanolic solution (20 $\mathrm{g} / \mathrm{l}$ ) was added to $0.5 \mathrm{ml}$ of faba bean ethanolic extract. The mixture was left for $1 \mathrm{hr}$., at room temperature, and then the absorbance was 
measured at $420 \mathrm{~nm}$ by the spectrophotometer. Total flavonoid content was expressed as $\mu \mathrm{g}$ quercetin equivalent $(\mathrm{QE}) / \mathrm{g}$ dry matter.

\section{Characterization and quantification of phenolic compounds by HPLC}

Individual phenolic compounds in the ethanolic extracts of non- irradiated faba bean seeds and those irradiated at dose of $9 \mathrm{kGy}$ were fractionated and quantified using a Hewlett Packard (HP 1100) HPLC instrument equipped with a $1100 \mathrm{HP}$ series ultraviolet diode array detector, an alpha bond $\mathrm{C}_{18} 125 \mathrm{~A}$ column $(4.6 \times$ $250 \mathrm{~mm}$, particle size $5 \mu \mathrm{m})$ and an Agilent 1100 series Chem Station software. The mobile phases were $2.0 \%$ acetic acid in distilled water (A) and acetonitrile (B). Sample was injected at volume of $20 \mu \mathrm{l}$ and the column was eluted under linear gradient conditions as described by Elbadrawy and Sello (2016). The detection of phenolic compounds was performed at $280 \mathrm{~nm}$ and identified by comparing their relative retention times with those of the standard mixture chromatogram. The concentration of an individual compound was calculated on the basis of peak area measurement and expressed as $\mu \mathrm{g}$ GAE/g dry extract.

\section{Characterization and quantification of flavonoid compounds by HPLC}

Fractionation and quantification of flavonoid compounds in ethanolic extracts of nonirradiated faba bean seeds and those irradiated at dose of $9 \mathrm{kGy}$ were performed by the same HPLC instrument. The mobile phase consisted of two solvents, $2 \%$ phosphate buffer at $\mathrm{pH} 3$ (A) and methanol (B), and the applied linear gradient conditions as described by Skerget $\boldsymbol{e t}$ al. (2005). The detection of compounds was performed at $367 \mathrm{~nm}$, then their quantification was made with an external standard and expressed as $\mu \mathrm{g} \mu \mathrm{g} \mathrm{QE} / \mathrm{g}$ dry extract.

\section{Chemical composition:}

The contents of moisture, protein, lipids and ash were determined in samples of nonirradiated and irradiated faba bean seeds according to the methods described by AOAC (2005). Total carbohydrates was calculated by difference between one hundred and summation of the percentages of moisture, protein, fat and ash. The contents of protein, lipids, ash, and carbohydrates were calculated on dry weight basis.

\section{Physical properties}

For all samples of non-irradiated and irradiated faba bean seeds, the hydration capacity, hydration index and swelling capacity were determined according to Sood et al. (2002). Swelling index of seeds was calculated according to Williams et al. (1983). Hydration and swelling coefficients were determined in faba bean seeds as described by Youssuf (1978).

\section{Statistical Analysis}

Data were statistically analyzed using the PROC ANOVA procedure of Statistical Analysis System (SAS, 1998).

\section{RESULTS AND DISCUSSION}

\section{Contents of Total Phenolic Compounds and Total Flavonoids in Faba Beans as Affected by Gamma Irradiation}

The contents of total phenolic compounds and total flavonoids in samples of non-irradiated and irradiated faba bean seeds were determined and the obtained results are shown in Table 1 . From these results, it could be seen that the contents of total phenolic compounds in samples of non-irradiated faba beans were $220.55 \pm 0.040$ $\mu \mathrm{g}$ GAE/g dry matter, while the total flavonoids in the non-irradiated samples were found to be $106.33 \pm 0.450 \mu \mathrm{g}$ QE/g dry matter. Several studies showed that faba bean is an important source of phenolic and flavonoid compounds and their levels largely varied in seeds of different varieties (Turco et al., 2016; Magalhães et al., 2017; Kwon et al., 2018).

The results in Table 1 further show the effect of gamma irradiation on the contents of total phenolic and flavonoid contents in faba bean. From these results, it is obvious that exposing faba bean seeds to the ascending doses of gamma radiation, significantly increased, the contents of total phenolic and flavonoid compounds in seeds. As shown, irradiation of faba bean seeds induced gradual increase in the total phenolic and flavonoids contents. The maximum increase was observed in samples irradiated at dose of $9 \mathrm{kGy}$ showing increase by 
Ali, et al.

Table 1. Contents of total phenolic and total flavonoids compounds in faba bean seeds as affected by gamma irradiation

\begin{tabular}{ccc}
\hline Irradiation dose (kGy) & \multicolumn{2}{c}{ Contents $($ Mean \pm SD) } \\
\cline { 2 - 3 } & $\begin{array}{c}\text { Total phenolics } \\
(\boldsymbol{\mu g} \text { GAE/g dry matter) }\end{array}$ & $\begin{array}{c}\text { Total flavonoids } \\
(\boldsymbol{\mu g} \text { QE/g dry matter })\end{array}$ \\
\hline $\mathbf{0}$ & $220.55 \pm 0.040 \mathrm{k}$ & $106.33 \pm 0.450 \mathrm{~K}$ \\
$\mathbf{1}$ & $255.71 \pm 0.710 \mathrm{~J}$ & $128.97 \pm 0.508 \mathrm{~J}$ \\
$\mathbf{2}$ & $288.46 \pm 0.070 \mathrm{I}$ & $164.90 \pm 0.825 \mathrm{I}$ \\
$\mathbf{3}$ & $319.94 \pm 0.040 \mathrm{H}$ & $190.38 \pm 0.825 \mathrm{H}$ \\
$\mathbf{4}$ & $357.58 \pm 0.030 \mathrm{G}$ & $208.76 \pm 0.676 \mathrm{G}$ \\
$\mathbf{5}$ & $394.03 \pm 0.030 \mathrm{~F}$ & $332.36 \pm 0.776 \mathrm{~F}$ \\
$\mathbf{6}$ & $432.90 \pm 0.600 \mathrm{E}$ & $271.33 \pm 1.074 \mathrm{E}$ \\
$\mathbf{7}$ & $478.60 \pm 0.400 \mathrm{C}$ & $311.72 \pm 0.740 \mathrm{D}$ \\
$\mathbf{8}$ & $519.29 \pm 0.710 \mathrm{~B}$ & $370.66 \pm 0.650 \mathrm{~B}$ \\
$\mathbf{9}$ & $623.64 \pm 0.090 \mathrm{~A}$ & $497.18 \pm 0.800 \mathrm{~A}$ \\
$\mathbf{1 0}$ & $460.07 \pm 0.070 \mathrm{D}$ & $343.29 \pm 0.710 \mathrm{C}$ \\
$\mathbf{L S D}$ & 2.6891 & 1.2407 \\
\hline
\end{tabular}

GAE: gallic acid equivalent. QE: quercetin equivalent.

about $183 \%$ and $283 \%$ in phenolic and flavonoids contents, respectively. Then significant decreases in these compounds started to appear in faba bean seeds irradiated at dose of $10 \mathrm{kGy}$. These results clearly indicated that the dose of $9 \mathrm{kGy}$ can be the optimum irradiation dose for increasing the contents of these compounds in faba bean. These results agree with different studies which reported the increase of phenolic and flavonoid contents in different plant seeds due to irradiation treatments (Bhat et al., 2007; Tresnia and Mohan, 2012; Tresina et al., 2017). The increase in phenolic compounds might be attributed to their higher extractability due to depolymerisation and dissolution of cell wall polysaccharides by irradiation (Siddhuraju et al., 2002). Also soluble phenols may resulted from the break of covalent bonds of polyphenolic components by irradiation leading to an increase in total phenolic contents (Jamshidi et al., 2014).

\section{Identification and Quantification of Phenolic and Flavonoid Compounds in the Ethanolic Extract of the Treated Faba bean}

\section{Phenolic compounds}

From the obtained results for total phenolic and flavonoid contents in non-irradiated and irradiated faba bean seeds, it is clear that irradiation dose of $9 \mathrm{kGy}$ can be selected as an optimum dose for increasing of these phytochemicals in faba bean. Therefore, the separation of phenolic and flavonoid compounds in the extracts from non-irradiated and $9 \mathrm{kGy}$ irradiated seeds was carried out by HPLC and the obtained results are shown in Tables 2 . From Table 2, it is obvious that 21 phenolic compounds could be separated from the extract of non-irradiated faba bean seeds by HPLC. The separated phenolic compounds were gallic acid, pyrogallol, 4-amino-benzoic, protocatchuic, catechin, chlorogenic acid, catechol, caffeine, PO-H-benzoic, caffeic,vanillic acid, p-cumaric, ferulic acid, iso-ferulic acid, ellagic acid, alphacumaric, benzoic acid, salicylic acid, 3,4,5methoxy-cinnamic, coumarin and cinnamic acid. The major phenolic compounds were found to be catechin, chlorogenic acid, pyrogallol, isoferulic acid, protocatchuic and salicylic acid and their concentrations were 1455.59, 631.6, 277.14, $159.45,144.11$ and $140.33 \mu \mathrm{g}$ GAE/g dry extract, respectively. The results in Table 2 further show that the same phenolic compounds were identified in the extract of seeds irradiated at $9 \mathrm{kGy}$ dose but the irradiation treatment increased the concentration of all phenolic components. 
Table 2. Identification and concenteration $(\mu \mathrm{g} / \mathrm{g}$ dry extract) phenolic of compounds in the ethanolic extract of non-irradiated and $9 \mathrm{kGy}$ irradiated faba bean seeds by HPLC

\begin{tabular}{lcc}
\hline Phenolic compound & \multicolumn{2}{c}{ Irradiation /Dose (kGy) } \\
\cline { 2 - 3 } & $\mathbf{0 ~ k G y}$ & $\mathbf{9 ~ K G y}$ \\
\hline Gallic acid & 33.31 & 64.36 \\
Pyrogallol & 277.14 & 893.35 \\
4- Amino-benzoic & 44.40 & 103.13 \\
Protocatchuic & 144.11 & 557.52 \\
Catechin & 1455.59 & 1782.58 \\
Chlorogenic acid & 631.60 & 1949.10 \\
Catechol & 161.97 & 318.83 \\
Caffeine & 136.78 & 463.02 \\
P-OH-benzoic & 97.62 & 426.05 \\
Caffeic & 87.71 & 281.63 \\
Vanillic acid & 130.19 & 680.55 \\
$P$ - cumaric & 16.95 & 68.89 \\
Ferulic acid & 49.96 & 231.21 \\
Iso- ferulic acid & 159.45 & 724.10 \\
Ellagic acid & 27.94 & 795.43 \\
Alpha-cumaric & 2.59 & 14.84 \\
Benzoic acid & 106.32 & 235.72 \\
Salicyllic acid & 140.33 & 421.54 \\
3, 4, 5-methoxy-cinnamic & 15.09 & 195.26 \\
Coumarin & 3.73 & 30.44 \\
Cinnamic acid & 0.92 & 2.75 \\
\hline & & \\
\hline & &
\end{tabular}

\section{Flavonoid compounds}

The identification of flavonoid compounds in the extracts of non-irradiated and $9 \mathrm{kGy}$ irradiated faba bean seeds was also carried out by HPLC analysis and the results are presented in Table 3. From this Table, it is noticeable that 14 flavonoid compounds were identified in the extract of non-irradiated faba bean samples. The identified compounds were Apig. 6- arabinose 8- glactose, Apig.6- rhamnose 8- glucose, Luteolin 7-glucose, Naringin, Rutin, Hespirdin, Apig.7-o-neohespiroside, Quercetrin, Quercetin,
Acacetin neo.rutinoside, Naringinin Hespirtin, Kampferol and Apegnin. The major compounds were Hespirdin, Naringin, Quercetrin, Luteolin 7- glucose, Apig.6- rhamnose 8- glucose, Rutin, Apig.6- arabinose - 8- glactose and Apig.7-oneohespiroside, and their amounts were 369.9, $169.12,43.31,36.98,30.11,23.91,16.67$ and $10.75 \mu \mathrm{g}$ QE/g dry extract, respectively. While the rest were found at concentration less than 10 $\mu \mathrm{g} \mathrm{QE} / \mathrm{g}$ dry extract. The results in Table 3 further show that the same flavonoid compounds were identified in the extract of faba bean seeds that received a radiation dose of $9 \mathrm{kGy}$. However, 
Table 3. Identification and concentration $(\mu \mathrm{g} / \mathrm{g}$ dry extract) of flavonoid compounds in the ethanolic extract of non-irradiated and $9 \mathrm{kGy}$ irradiated faba bean seeds by HPLC

\begin{tabular}{lcc}
\hline Flavonoid compound & \multicolumn{2}{c}{ Irradiation/Dose (kGy) } \\
\cline { 2 - 3 } & $\mathbf{0 ~ k G y}$ & $\mathbf{9}$ KGy \\
\hline Apig.6- arabinose - 8- glactose & 16.67 & 153.73 \\
Apig.6- rhamnose 8- glucose & 30.11 & 99.97 \\
Luteolin 7- glucose & 36.98 & 294.70 \\
Naringin & 169.12 & 463.11 \\
Rutin & 23.91 & 58.43 \\
Hespirdin & 369.90 & 5082.31 \\
Apig.7-o-neohespiroside & 10.75 & 50.23 \\
Quercetrin & 43.31 & 232.24 \\
Quercetin & 4.24 & 31.56 \\
Acacetin neo.rutinoside & 9.20 & 63.30 \\
Naringinin & 0.87 & 10.36 \\
Hespirtin & 4.95 & 40.33 \\
Kampferol & 1.55 & 24.53 \\
Apegnin & 1.84 & 12.83 \\
\hline
\end{tabular}

the concentration of all flavonoid compounds increased by this irradiation treatment.

Many previous studies showed different profiles for phenolic and flavonoid components in faba bean extracts (El-Mergawi and Taie, 2014; Pasricha et al., 2014; Magalhăes et al., 2017; Kan et al., 2018). This may reflect the effect of different factors, including those of climatic, environmental and genotype differences, on the variations in these compounds. Magalhăes et al. (2017) also showed that each variety of faba bean presented different phenolic profiles. Meanwhile, the increase in phenolics might be observed from the release of phenolic compounds from glycosidic components as illustrated by Harrison and Were (2007).

\section{Effect of Gamma Irradiation on Chemical Composition of Faba bean}

The proximate chemical composition was determined in samples of non-irradiated and irradiated faba beans and the results are presented in Table 4. As shown, the content of moisture in samples of non-irradiated faba beans was $8.756 \pm 0.097 \%$, while the percentages of total fat, ash, protein and carbohydrates in the non-irradiated faba bean samples reached 4.194 $\pm 0.058,3.825 \pm 0.030,33.171 \pm 0.503$ and $58.81 \pm 0.478 \%$ on dry weigh basis, respectively. It has been reported that the contents of protein, lipids and carbohydrates in faba bean seeds were in the range of 20-41,1.2-4 and 51-68 \%, respectively, as illustrated by Turco et al. (2016). Moreover, the chemical composition of plant foods is influenced by many factors including cultivar and genotype, environment and irrigation conditions (Longobardi et al., 2015; Vonapartis et al., 2015; Mattila et al., 2018).

The results in Table 4 also show that significant, differences were observed in the proximate chemical composition between samples of non-irradiated faba beans and those subjected to gamma irradiation at doses up to 10 kGy. The observed differences may be due to differences between samples. Similar results were 
Zagazig J. Agric. Res., Vol. 46 No. (3) 2019

Table 4. Chemical composition of faba beans as affected by gamma irradiation

\begin{tabular}{cccccc}
\hline Irradiation & \multicolumn{5}{c}{ Component (\%) (Mean \pm SD) } \\
\cline { 2 - 6 } Dose (kGy) & Moisture & Fat & Ash & Protein & Carbohydrates \\
\hline $\mathbf{0}$ & $8.756 \pm 0.097 \mathrm{~A}$ & $4.194 \pm 0.058 \mathrm{~A}$ & $3.825 \pm 0.030 \mathrm{~F}$ & $33.171 \pm 0.530 \mathrm{~A}$ & $58.81 \pm 0.478 \mathrm{D}$ \\
$\mathbf{1}$ & $8.736 \pm 0.080 \mathrm{~A}$ & $4.127 \pm 0.051 \mathrm{AB}$ & $3.904 \pm 0.055 \mathrm{E}$ & $32.397 \pm 0.681 \mathrm{ABC} 59.572 \pm 596 \mathrm{CD}$ \\
$\mathbf{2}$ & $8.663 \pm 0.054 \mathrm{AB}$ & $4.065 \pm 0.035 \mathrm{BC}$ & $3.955 \pm 0.055 \mathrm{CE}$ & $32.444 \pm 0.513 \mathrm{AB}$ & $59.536 \pm 0.509 \mathrm{CD}$ \\
$\mathbf{3}$ & $8.620 \pm 0.050 \mathrm{~B}$ & $4.012 \pm 0.032 \mathrm{CD}$ & $3.957 \pm 0.045 \mathrm{CE}$ & $31.918 \pm 0.351 \mathrm{BC}$ & $60.113 \pm 0.407 \mathrm{BC}$ \\
$\mathbf{4}$ & $8.636 \pm 0.061 \mathrm{BC}$ & $3.965 \pm 0.045 \mathrm{DE}$ & $3.974 \pm 0.040 \mathrm{BC}$ & $32.070 \pm 0.200 \mathrm{BC}$ & $59.991 \pm 0.198 \mathrm{BC}$ \\
$\mathbf{5}$ & $8.646 \pm 0.037 \mathrm{AB}$ & $3.901 \pm 0.038 \mathrm{EF}$ & $4.014 \pm 0.035 \mathrm{ABC} 31.854 \pm 0.300 \mathrm{BC}$ & $60.231 \pm 0.340 \mathrm{BC}$ \\
$\mathbf{6}$ & $8.523 \pm 0.065 \mathrm{CD}$ & $3.903 \pm 0.040 \mathrm{E}$ & $3.985 \pm 0.050 \mathrm{BC}$ & $31.811 \pm 0.040 \mathrm{BC}$ & $60.301 \pm 0.366 \mathrm{ABC}$ \\
$\mathbf{7}$ & $8.463 \pm 0.080 \mathrm{DE}$ & $3.813 \pm 0.060 \mathrm{FG}$ & $3.945 \pm 0.040 \mathrm{CE}$ & $31.644 \pm 0.351 \mathrm{BC}$ & $60.598 \pm 0.279 \mathrm{AB}$ \\
$\mathbf{8}$ & $8.419 \pm 0.007 \mathrm{DE}$ & $3.774 \pm 0.050 \mathrm{GH}$ & $4.025 \pm 0.057 \mathrm{AB}$ & $31.412 \pm 0.351 \mathrm{BC}$ & $60.789 \pm 0.432 \mathrm{AB}$ \\
$\mathbf{9}$ & $8.386 \pm 0.065 \mathrm{E}$ & $3.772 \pm 0.025 \mathrm{GH}$ & $3.991 \pm 0.050 \mathrm{BC}$ & $31.691 \pm 0.907 \mathrm{BC}$ & $60.546 \pm 9.001 \mathrm{AB}$ \\
$\mathbf{1 0}$ & $8.253 \pm 0.066 \mathrm{~F}$ & $3.684 \pm 0.030 \mathrm{H}$ & $4.050 \pm 0.040 \mathrm{~A}$ & $31.209 \pm 0.451 \mathrm{C}$ & $61.057 \pm 0.434 \mathrm{~A}$ \\
$\mathbf{L S D}$ & 0.1084 & 0.0741 & 0.0546 & 0.8337 & 0.8579 \\
\hline
\end{tabular}

Contents of fat, protein, ash and carbohydrates were calculated on dry weight basis.

reported by Al-Kaisey et al. (2003) as they showed that no major differences were observed between the chemical composition of nonirradiated broad bean seeds and those irradiated at doses up to $10 \mathrm{kGy}$.

\section{Water Absorption Properties of Faba beans as Affected by Gamma Irradiation}

The effect of gamma irradiation treatments on water absorption properties as measured gravimetrically (hydration properties) and volumetrically (swelling properties) was determined for faba bean seeds (Tables 5 and 6). As it could be seen from Table 5, the values of hydration capacity, hydration index and hydration coefficient showed general slight, but statistically significant, increases in samples of irradiated faba bean seeds when compared with those for the non-irradiated samples. The same observation was noticed for the values of swelling capacity, swelling index and swelling coefficient for faba bean seeds which also showed general slight, but statistically significant, increases in irradiated samples as compared with non-irradiated ones (Table 6). Similar observations were reported by Kŏksel and
Çelik (2011) for dry beans and Tresina and Mohan (2012) for irradiated Vigna unguiculata subsp. unguiculata seeds. It has been illustrated that such increase in water absorption might be related to degradation of starch (Tresina and Mohan, 2012). It is well known that water retention capacity or hydration capacity determine the swelling ability of any seeds and constitute important characteristics for their processing. Legumes with high hydration and swelling coefficients require less cooking time (Shimelis and Rakshit, 2005; Nciri et al., 2014).

\section{Conclusion}

From these results, it could be concluded that treatment of faba bean seeds by gamma irradiation significantly increased their contents of phenolic and flavonoid compounds. In addition, irradiation treatments had no detrimental effects on the proximate chemical composition of faba bean seeds, while generally induced slight, but statistically significant, increases in their values for water absorption properties. 
Table 5. Effect of gamma irradiation on hydration properties of faba bean seeds

\begin{tabular}{cccc}
\hline Irradiation dose (kGy) & \multicolumn{3}{c}{ property (Mean \pm SD) } \\
\cline { 2 - 4 } & Hydration capacity (g/seed) & Hydration index & Hydration coefficient (\%) \\
\hline 0 & $0.566 \pm 0.004 \mathrm{DE}$ & $0.631 \pm 0.005 \mathrm{DE}$ & $176.68 \pm 0.301 \mathrm{~F}$ \\
1 & $0.562 \pm 0.003 \mathrm{E}$ & $0.667 \pm 0.006 \mathrm{C}$ & $177.26 \pm 0.251 \mathrm{EF}$ \\
2 & $0.592 \pm 0.003 \mathrm{AB}$ & $0.701 \pm 0.003 \mathrm{~A}$ & $177.79 \pm 0.261 \mathrm{E}$ \\
3 & $0.572 \pm 0.005 \mathrm{CD}$ & $0.623 \pm 0.005 \mathrm{EF}$ & $177.65 \pm 0.350 \mathrm{E}$ \\
4 & $0.554 \pm 0.003 \mathrm{~F}$ & $0.609 \pm 0.005 \mathrm{~F}$ & $173.36 \pm 0.814 \mathrm{G}$ \\
5 & $0.591 \pm 0.005 \mathrm{AB}$ & $0.662 \pm 0.006 \mathrm{C}$ & $179.58 \pm 0.520 \mathrm{D}$ \\
6 & $0.577 \pm 0.005 \mathrm{C}$ & $0.664 \pm 0.006 \mathrm{C}$ & $179.50 \pm 0.500 \mathrm{D}$ \\
7 & $0.585 \pm 0.005 \mathrm{~B}$ & $0.687 \pm 0.007 \mathrm{AB}$ & $180.23 \pm 0.057 \mathrm{CD}$ \\
8 & $0.587 \pm 0.003 \mathrm{~B}$ & $0.691 \pm 0.004 \mathrm{AB}$ & $180.66 \pm 0.577 \mathrm{BC}$ \\
9 & $0.598 \pm 0.003 \mathrm{~A}$ & $0.678 \pm 0.003 \mathrm{BC}$ & $181.66 \pm 0.577 \mathrm{~A}$ \\
10 & $0.587 \pm 0.005 \mathrm{~B}$ & $0.643 \pm 0.005 \mathrm{D}$ & $181.26 \pm 0.251 \mathrm{~A}$ \\
$\mathrm{LSD}$ & 0.0075 & 0.0178 & 0.8743 \\
\hline
\end{tabular}

Table 6. Effect of gamma irradiation on swelling properties of faba bean seeds

\begin{tabular}{cccc}
\hline Irradiation dose (kGy) & \multicolumn{3}{c}{ property (Mean \pm SD) } \\
\cline { 2 - 4 } & Swelling capacity (g/seed) & Swelling index & Swelling coefficient (\%) \\
\hline 0 & $0.604 \pm 0.002 \mathrm{G}$ & $0.727 \pm 0.004 \mathrm{~F}$ & $194.78 \pm 0.623 \mathrm{E}$ \\
1 & $0.640 \pm 0.008 \mathrm{~F}$ & $0.768 \pm 0.011 \mathrm{E}$ & $196.24 \pm 2.27 \mathrm{E}$ \\
2 & $0.677 \pm 0.104 \mathrm{C}$ & $0.814 \pm 0.011 \mathrm{C}$ & $210.03 \pm 1.39 \mathrm{C}$ \\
3 & $0.653 \pm 0.009 \mathrm{E}$ & $0.784 \pm 0.003 \mathrm{D}$ & $205.88 \pm 0.00 \mathrm{D}$ \\
4 & $0.660 \pm 0.009 \mathrm{DE}$ & $0.791 \pm 0.011 \mathrm{D}$ & $206.76 \pm 1.32 \mathrm{D}$ \\
5 & $0.674 \pm 0.005 \mathrm{C}$ & $0.807 \pm 0.004 \mathrm{C}$ & $211.56 \pm 1.62 \mathrm{BC}$ \\
6 & $0.673 \pm 0.009 \mathrm{DC}$ & $0.807 \pm 0.010 \mathrm{C}$ & $212.54 \pm 1.35 \mathrm{~B}$ \\
7 & $0.680 \pm 0.004 \mathrm{C}$ & $0.817 \pm 0.004 \mathrm{C}$ & $212.15 \pm 0.68 \mathrm{CB}$ \\
8 & $0.694 \pm 0.005 \mathrm{~B}$ & $0.834 \pm 0.008 \mathrm{~B}$ & $218.75 \pm 0.00 \mathrm{~A}$ \\
9 & $0.703 \pm 0.008 \mathrm{AB}$ & $0.842 \pm 0.009 \mathrm{~A}$ & $219.58 \pm 1.44 \mathrm{~A}$ \\
10 & $0.710 \pm 0.011 \mathrm{~A}$ & $0.851 \pm 0.014 \mathrm{~A}$ & $213.68 \pm 1.81 \mathrm{~B}$ \\
$\mathrm{LSD}$ & 0.0129 & 0.0152 & 2.2559 \\
\hline
\end{tabular}




\section{REFERENCES}

Abu-Reidah, I.M., D. Arráez-Román, I. Warad, A. Fernández-Gutiérrez and A. SeguraCarretero (2017). UHPLC/MS ${ }^{2}$ - based approach for the comprehensive metabolite profiling of bean (Vicia faba L.) by-products: A promising source of bioactive constituents. Food Res. Int., 93: 87-96.

Al-Kaisey, M.T., A.H. Alwan, M.H. Mohammed and A.H. Saeed (2003). Effect of gamma irradiation on antinutritional factors in broad bean. Radiation Physics and CheM., 67: 493496.

AOAC (2005). Official Methods of Analysis, Association of Official Analytical Chemists, $18^{\text {th }}$ Ed., Virginia, USA.

Arabshahi-Delouee, S and A. Urooj (2007). Antioxidant properties of various solvent extracts of mulberry (Mocus indica L.) leaves. Food Chem., 102: 1233-1244.

Bhat, R., K.R. Sridhar and K. Tomita-Yokotani (2007). Effect of ionizing radiation on antinutritional features of velvet been seeds (Mucuna prariens L.). Food Chem., 103 (3): 860-866.

Chaieb, N., M. López-Mesas, J.L. González, M. Mars and M. Valiente (2015). Hollow fiber liquid phase micro-extraction by facilitated anionic exchange for the determination of flavonoids in faba beans (Vicia faba L.). Phytochemical Anal., 26: 346-352.

De Rosas, M.I., L. Deis, L. Martínez, M. Durán, E. Malovini and J.B. Cavagnaro (2019). Anthocyanins in Nutrition: Biochemistry and Healthenefits. In: Gargiulo, P, A and Arroyo, HLM. (eds.), Psychiatry and Neuroscience Update, Springer Nature, Switzerland AG, 143-152.

Ehlermann, D.A.E. (2016). Wholesomeness of irradiated food. Radiation Physics and Chem., 125: 24-29.

Elbadrawy, E. and A. Sello (2016). Evaluation of nutritional value and antioxidant activity of tomato peel extracts. Arab. J. Chem., 9: 1010-1018.

El-Mergawi, R. and A.A.H. Taie (2014). Phenolic composition and antioxidant activity of raw seeds, green seeds and sprouts of ten faba bean (vicia faba L.) cultivars consumed in Egypt. Int. J. Pharma and Bio Sci., 5 (2): (B) 609-617.

Grela, E.R., W. Samolińska, B. Kiczorowska, R. Klebaniuk and P. Kiczorowski, (2017). Content of minerals and fatty acids and their correlation with phytochemical compounds and antioxidant activity of leguminous seeds. Biological Trace Element Res., 180: 338-348.

Guti Errez-Grijalva, E.P., D.L. Ambriz-Pere, N. Leyva-Lopen, R.I. Castillo-Lopez and J.B. Heiedia, (2016). Review: dietary phenolic compounds, health benefits and bioaccessibility. Archivos Latinoamericanos De Nutrición, 66 (2): 87-100.

Ha, L.T.N. (2016). Phenolic compounds and human health. Viet. J. Agric. Sci., 14 (7): 1107-1118.

Harrison, K and L.M. Were (2007). Effect of gamma irradiation on total phenolic content yield and antioxidant capacity of almond skin extracts. Food Chem., 120 (3): 932-937.

Hu, J., S.J. Kwon, J.J. Park, E. Landry, D.S. Mattinson and D.R. Gang (2015). LC-MS determination of L-DOPA concentration in the leaf and flower tissues of six faba bean (Vicia faba L.) lines with common and rare flower colors. Functional Foods in Health and Diseases, 5: 243-250.

Jamshidi, M., M. Barzegar and M.A. Sahari (2014). Effect of gamma microwave irradiation on antioxidant and antimicrobial activity of Cinnamomum zeylanicum and Echinacea purpurea. Int. Food Res. J., 21 (4): 1289-1296.

Kan, L., S. Nie, J. Hu, S. Wang, Z. Bai, J. Wang, Y. Zhou, J. Jiang and K. Song (2018). Comparative study on the chemical composition, anthocyanins, tochopherols and carotenoids of selected legumes. Food Chem., 260 : 317-326.

Kŏksel, H. and S. Çelik (2011). Quality evaluation of gamma-irradiated food legumes. GIDA, 26 (3): 151-155.

Kwon, S-J., D-G. Kim, J-M. Kim, K-Y. Kang, M-K. Lee, M.J. Hong, J-B. Kim, S.H. Eom, 
S-Y. Kang, B-K. Ha and J. Ryu (2018). Phytochemical compounds and antioxidant activity in the grain of selected faba bean (Vicia faba) genotypes. Plant Breeding and Biotechnol., 6 (1): 65-73.

Kume, T. and S. Todoriki (2013). Food irradiation in Asia, the European Union, and the United States: A status update. Radioisotops, 62 : 291-299.

Longobardi, F., D. Sacco, G. Casiello, A. Ventrella and A. Sacco (2015). Chemical profile of the carpino broad bean by conventional and innovative physico chemical analysis. J. Food Quality, 38: 273284.

Magalhăes, S.C.Q., M. Taveira, A.R.J. Cabrita, A.J.M. Fonseca, P. Valentão and P.B. Andrade (2017). European marketable grain legume seeds. Further insight into phenolic compounds profiles. Food Chem., 215 : 177184.

Maherani, B., F. Hossain, P. Criado, Y. BenFadhel, S. Salmieri and M. Lacroix (2016). World market development and consumer acceptance of irradiation technology. Foods, 5: 79: 1-21.

Martins, N. and I.C.F.R. Ferreira (2017). Neurocognitive improvement through plant food bio actives: a particular approach to Alzheimer's disease. In: Puri, M. (Ed.), Food Bio-actives, Springer Int. Publishing AG.

Mattila, P., S. Mäkinen, M. Eurola, T. Jalava, J-M. Pihlava, J. Hellströmy and A. Pihlanto (2018). Nutritional value of commercial protein-rich plant products. Plant Foods for Human Nutr., 73: 108-115.

Nciri, N., F. El-Mhamdi, H. Ben Ismail, A. Ben Mansour and F. Fennira (2014). Physical properties of three white bean varieties (Phaseolus vulgaris L.) grown in Tunisia. J. Appl. Sci. and Agric., 9 (11): 195-200.

Oomah, D.B., C. Blanchard and P. Balasubramanian (2008). Phytic acid, phytase, minerals, and antioxidant activity in Canadian dry bean (Phaseolus vulgaris L.) cultivars. J. Agric. and Food Chem., 56: 11312 - 11319.

Ordon, J.D., M.A. Gomez and M.I. Vattuone (2006). Antioxidant activities of Sechiumedule
(Jacq.) Swartz extracts. Food Chem., 97: 452 -458 .

Osterholm, M.T. and A.P. Norgan (2004). The role of irradiation in food safety. New England J. Med., 350: 1898-1901.

Pasricha, V., G. Satpathy and R.K.Gupta (2014). Phytochemical and antioxidant activity of underutilized legume Vicia faba L. seeds and formulation of its fortified biscuits. J. Pharmacognosy and Phytochem., 3 (2): 75-80.

Pereira, E., A. Antonio, J.G.M. Barreira and C. Santos-Buelga (2018b). How gamma and electron-beam irradiations modulate phenolic profile expression in Melissa officinalis L. and Melittis melissiophyllum L. Food Chem., 240: 253-258.

Pereira, E., A. Pimenta, L. Barros, R.C. Calhelha, A.L. Antonio, S.C. Verde and I.C.F.R. Ferreira (2018a). Effect of gamma irradiation on the bioactivity of medicinal and aromatic plants: Mentha xpiperita L., Thymus vulgaris L. and Aloysia citrodora palău as case studies. Food and Function, 10: 5156-5161.

SAS Program (1998). SAS/STAT User's Guide Release 8.2 Ed. Cary, NC, SAS Inst. Inc. USA.

Shimelis, E.A. and S.K. Rakshit (2005). Proximate composition and physicochemical properties of improved dry bean (Phaseolus vulgaries L.) varieties grown in Ethiopia. LWT-Food Sci. and Technol., 38 (4): 331-338.

Siddhuraju, P., O. Osoniyi, J.P.S. Makkar and K. Becker (2002). Effect of soaking and ionizing radiation on various anti-nutritional factors of seeds from different species of an un-conventional legume, sesbania and a common legume, green gram (Vigna radiate L.). Food Chem., 79 (3): 273-281.

Skerget, M., P. Kotnik, M. Hadolin, A.R. Hras, M. Simonic and Z. Knez (2005). Phenols, proanthocyanidins, flavones and flavonols in some plant materials and their antioxidant activities. Food Chem., 89: 191-198.

Sood, M., S.R. Malhotra and B.C. Sood (2002). Effect of processing and cooking on proximate composition of chickpea (Cicer 
arietinum) varieties. J. Food Sci. and Technol., 39: 69-71.

Tresina, P.S. and V.R. Mohan (2012). Physicochemical and anti-nutritional attributes of gamma irradiated Vigna mngmiculata (L.) Walp. Subsp. Mnguiculata seed. Int. Food Res. J., 19 (2): 639-646.

Tresina, P.S., K. Paulpriya, V.R. Mohan and S. Jeeva (2017). Effect of gamma irradiation on the nutritional and antinutritional qualities of Vigna aconititolia (Jacq.) Marchal: An underutilized food legume. Biocatalysis and Agric. Biotechnol., 10: 30-37.

Turco, I., G. Ferretti and T. Bacchetti (2016). Review of the health benefits of faba bean (Vicia faba L.) polyphenols. J. Food and Nutr. Res., 55 (4): 283-293.

Vardhan, P.V. and L.I. Shukla (2017). Gamma irradiation medicinally important plants and the enhancement of secondary metabolite production. Int. J. Rad. Biol., 93 (9):967-979.

Vonapartis, E., M. Aubin, P. Seguin, A.F. Mustafa and J. Charron (2015). Seed composition of ten industrial hemp cultivars approved for production in Canada. J. Food Comp. and Anal., 39: 8-12.

Williams, P.C., H. Nakoul and K.B. Singh (1983). Relationship between cooking time and some physical characteristics in chickpeas (Cicer arietinum L.). J. Sci. Food and Agric., 34 (5): 492-496.

Woodside, J. (2015). Nutritional aspects of irradiated food. Stewart Postharvest Review, 3 (2): 1-6.

Youssuf, M.M. (1978). A Study of Factors Affecting the Cook Ability of Faba Beans (Vicia faba L.), Ph.D. Thesis, Fac. Agric., Alex. Univ., Egypt.

Zevallos-Concha, A., N.M. Gasco, C. Vasquez, M. Quispe and G.F. Gonzales (2016). Effect of gamma irradiation on phenolic content, antioxidant activity and biological activity of black maca and red maca extracts (Lepidium meyenii walp). Toxicol. Mechanisms and Methods, 26 (1): 67-73.

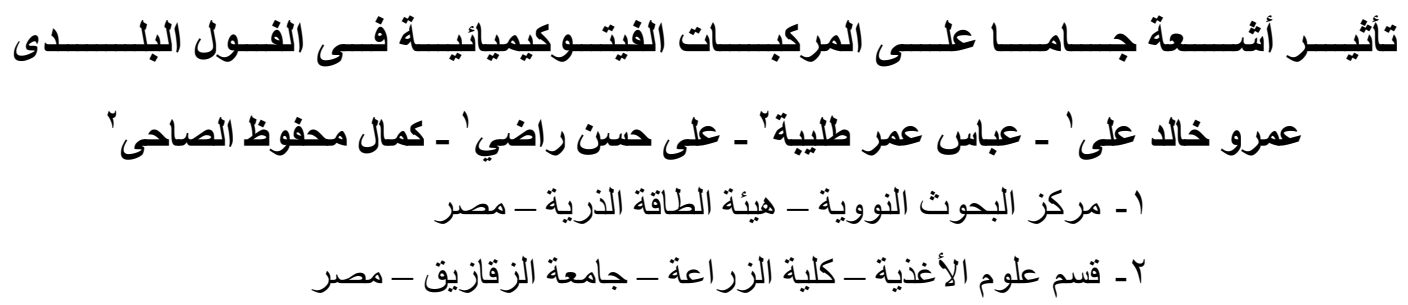

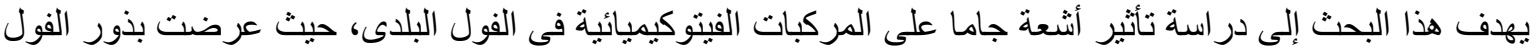

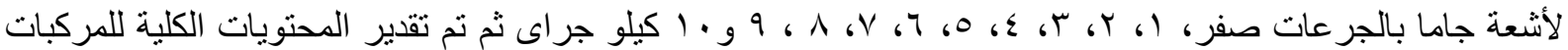

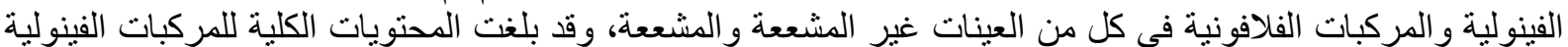

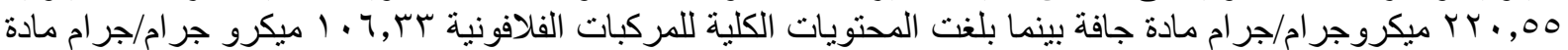

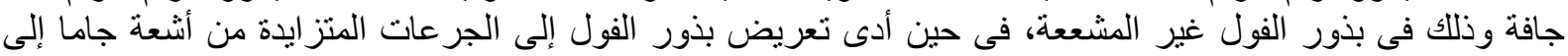

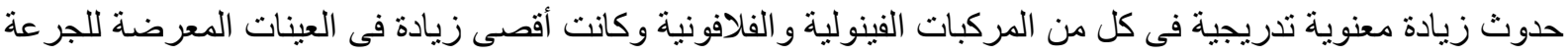

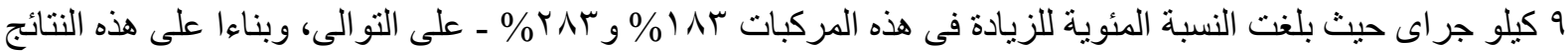

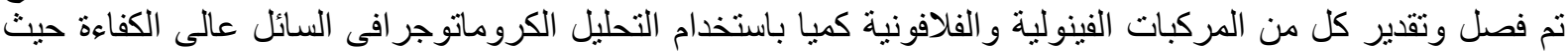

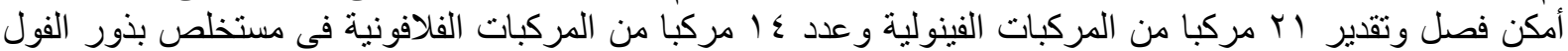

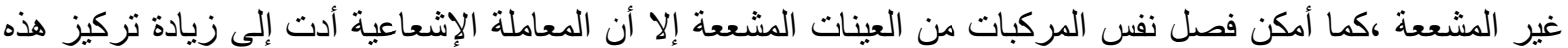

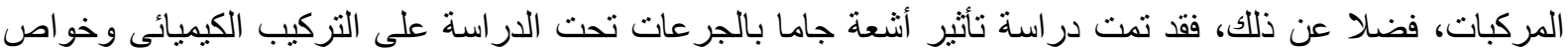

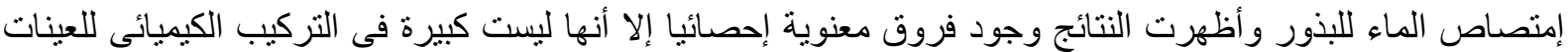

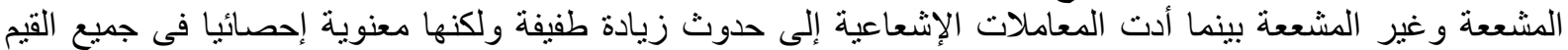

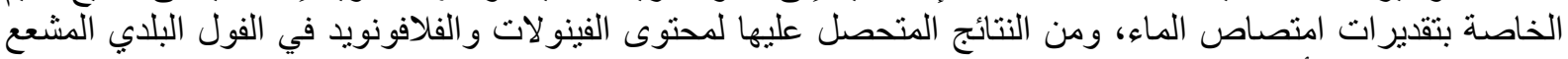

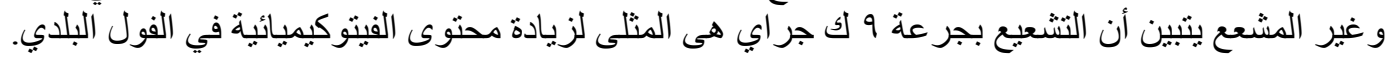

